\title{
The anticancer agent YC-1 suppresses progestin-stimulated VEGF in breast cancer cells and arrests breast tumor development
}

\author{
CANDACE E. CARROLL ${ }^{1}$, YAYUN LIANG ${ }^{1}$, INDIRA BENAKANAKERE ${ }^{1}$, \\ CYNTHIA BESCH-WILLIFORD ${ }^{2}$ and SALMAN M. HYDER ${ }^{1}$ \\ ${ }^{1}$ Department of Biomedical Sciences and Dalton Cardiovascular Research Center, \\ University of Missouri, Columbia, MO 65211; ${ }^{2}$ IDEXX RADIL, Columbia, MO 65201, USA
}

Received August 2, 2012; Accepted September 4, 2012

DOI: $10.3892 /$ ijo.2012.1675

\begin{abstract}
Recent epidemiological studies show that postmenopausal women taking estrogen-progestin hormone replacement therapy (HRT) have a higher risk of breast cancer than women on an HRT regimen lacking progestins. This may be related to the observation that progestin-treated breast cancer cells express and secrete high levels of vascular endothelial growth factor (VEGF), a potent angiogenic factor that promotes breast tumor growth. Anti-progestins such as RU-486 block this effect, indicating that progesterone receptors (PR) are involved in promoting VEGF induction; however antiprogestins crossreact with other steroid receptors which limits their clinical use. Alternative strategies are, therefore, needed to arrest the growth of progestin-dependent tumors. 3-(5'-hydroxymethyl-2'-furyl)1-benzylindazole (YC-1), a novel anticancer drug initially developed as an inhibitor of HIF-1 $\alpha$, is currently undergoing preclinical trials against various forms of cancer. Since HIF-1 $\alpha$ has recently been implicated in PR-mediated VEGF synthesis, we undertook studies to determine whether YC-1 inhibits progestin-dependent VEGF induction and tumor progression. Surprisingly, we found that YC-1 downregulated PR in human breast cancer cells, both in vivo and in vitro, thereby blocking progestin-dependent induction of VEGF and tumor growth. YC-1 also inhibited progestin-accelerated DMBA-induced mammary tumors in rats, properties which would likely render it effective against progestin-dependent tumors which frequently develop in post-menopausal women. We, therefore, propose that based on our observations, YC-1 warrants further investigation as a novel agent which could prove extremely useful as an antiangiogenic chemotherapeutic drug.
\end{abstract}

\section{Introduction}

Hormone replacement therapy (HRT) containing either estrogen alone or a combination of estrogen and a progestin

Correspondence to: Dr Salman M. Hyder, Dalton Cardiovascular Research Center, 134 Research Park Drive, Columbia, MO 65211, USA E-mail: hyders@missouri.edu

Key words: YC-1, progestins, progesterone receptors, VEGF, breast cancer such as medroxyprogesterone acetate (MPA), is a commonlyused treatment for menopause in women (1). Clinical studies show that estrogen-based HRT is associated with increased risk of uterine cancer, while there is an elevated risk of breast cancer, metastasis and mortality in women undergoing estrogen/progestin-based HRT (2-4). Our recent studies show that progestins induce in vitro expression of vascular endothelial growth factor (VEGF), a potent angiogenic growth factor, in a subset of human breast cancer cells that express mutant p53 $(5,6)$ and stimulate breast tumor growth in vivo $(7,8)$. Conversely, the anti-progestin RU-486 and anti-VEGF antibodies inhibit secretion and function of VEGF in vitro and block breast tumor growth in vivo $(7,8)$. These results support the hypothesis that pharmacological use of progestins increases the risk of progesterone receptor (PR)-dependent breast cancer in postmenopausal women by a mechanism involving induction of VEGF. Though anti-progestins such as mifepristone or RU-486 suppress progestin-dependent actions, their use is limited due to a number of side effects that occur as a result of cross-reactivity with other steroid receptors (9). Thus other means of controlling PR mediated effects are being explored.

Hypoxia-inducible factor- $1 \alpha(\mathrm{HIF}-1 \alpha)$, is a basic helixloop-helix transcription factor that regulates expression of VEGF and other genes that modulate growth, survival and metastasis of tumor cells under conditions of hypoxia $(10,11)$. Under normoxic conditions, HIF- $1 \alpha$ is rapidly degraded, but under hypoxic conditions, HIF- $1 \alpha$ dimerizes with and is stabilized by HIF-1 $\beta$, and the HIF- $1 \alpha, \beta$ heterodimer actively regulates expression of promoters containing its cognate response element, hypoxia-response element (HRE) (12) that is also located in the VEGF promoter. Several studies suggest that HIF-1 $\alpha$ regulates expression of VEGF in cancer cells $(13,14)$. 3-(5'-hydroxymethyl-2'-furyl)-1-benzylindazole (YC-1) (15) was initially developed as a specific HIF-1 $\alpha$ inhibitor which interferes with binding of HIF-1 $\alpha$ to promoter regions of its target genes (10). However, YC-1 has been found to possess additional properties; it is also a nitric oxide synthetase (NOS)-independent activator of soluble guanylyl cyclase (sGC), which has been used clinically to treat thrombosis and hypertension (16), and it blocks NF- $\kappa$ B activity in tumor cells (17). Importantly, previous studies suggest that YC-1 may have significant anti-tumor activity by targeting HIF- $1 \alpha$ and $\mathrm{NF}-\kappa \mathrm{B}$ transcription factors (18). 
Recent studies in a bovine model have shown that HIF-1 $\alpha$ plays a role in PR mediated VEGF induction (13). With this in mind we used cell culture techniques and rodent models to examine, both in vitro and in vivo, the capacity of YC-1 as a HIF-1 $\alpha$ inhibitor which might be used to control progestinstimulated PR-dependent VEGF secretion and progression of progestin-dependent breast cancer. Breast cancer cells were exposed to YC-1 in vitro or in vivo and their growth and tumorigenic properties examined. Unexpectedly we made the novel observation that, both in vivo and in vitro, YC-1 downregulates PR in human breast cancer cells. Furthermore, YC-1 arrests the progression of progestin-dependent breast cancer cells in vivo by preventing VEGF induction which depends upon progestin activity.

\section{Materials and methods}

Materials. Human T47-D and BT-474 breast cancer cell lines were obtained from ATCC (Manassas, VA). 3-(5'-hydroxymethyl-2'-furyl)-1-benzylindazole) (YC-1), was purchased from Biomol International, LP (Plymouth Meeting, PA). Phenol redfree DMEM/F12 medium, phosphate-buffered saline and $0.05 \%$ trypsin-EDTA were purchased from Invitrogen Corporation and Life Technologies (Grand Island, NY). Fetal bovine serum (FBS) was obtained from JRH Biosciences (Lenexa, KS).

Cell viability assay. T47-D and BT-474 human breast cancer cells were exposed to YC-1 $(1-100 \mu \mathrm{M})$ for $18 \mathrm{~h}$ and cell viability was tested using the sulforhodamine B (SRB) assay $(19,20)$.

Cell culture and VEGF ELISA. Cells were grown in DMEM/ $\mathrm{F} 12+10 \%$ FBS for routine culture. Media was replaced with DMEM/F12 containing 5\% dextran-coated charcoal (DCC)treated serum for $24 \mathrm{~h}$ prior to treatment of cells in triplicate with progestins and inhibitors for a further $18 \mathrm{~h}$. Media was collected and ELISA for VEGF performed using a VEGF ELISA kit from R\&D Systems, Inc. (Minneapolis, MN) as previously described (21-23). According to the manufacturer's protocol, the minimum detectable concentration of VEGF is less than $5 \mathrm{pg} / \mathrm{ml}$, the intra-assay precision has a coefficient of variance (CV \%) between 3.5-6.5\%, while the CV \% of the inter-assay ranges from 5.0 to $8.5 \%$.

Bicinchoninic acid (BCA) protein assay. BCA assay using bovine serum albumin as a standard was used to determine total protein concentrations as described before (21-23). All samples were analyzed in duplicate.

Preparation of whole cell extract for western blot analysis. Whole cell extracts were prepared with a nuclear extract kit (Active Motif). Briefly, cells were grown in $100 \mathrm{~mm}$ culture dish overnight and then treated with DMEM/F12 containing 5\% FBS-DCC serum for $24 \mathrm{~h}$. Cells were then treated with $10 \mathrm{nM}$ MPA alone and in the presence of $100 \mu \mathrm{M}$ YC-1, or YC-1 alone for $6 \mathrm{~h}$. At the end of treatments, cells were washed with icecold PBS containing phosphatase inhibitors (with kit), harvested by gentle scraping with a cell lifter, and centrifuged for $5 \mathrm{~min}$ at $200 \mathrm{x} \mathrm{g}$ at $4^{\circ} \mathrm{C}$. Cell pellets were re-suspended in complete lysis buffer (provided in the TransAm kit; $1 \mathrm{mM}$ DTT and 1\% protease inhibitor cocktail was added prior to use) and incu- bated on ice for $30 \mathrm{~min}$ with shaking. Samples were centrifuged at $14,000 \mathrm{x}$ g for $15 \mathrm{~min}$, and the supernatant was transferred to a microcentrifuge tube, aliquoted, and stored at $-80^{\circ} \mathrm{C}$.

Western blotting. Proteins (50 $\mu \mathrm{g}$ per lane) were separated in a $10 \%$ NuPAGE Bis-Tris Gel (Invitrogen, Carlsbad, CA). Electrophoresis was performed at $120 \mathrm{~V}$ for $1.5 \mathrm{~h}$ using NuPAGE MOPS-SDS Running Buffer. Separated proteins were transferred to polyvinylidene difluoride membranes (Bio-Rad Laboratories, Hercules, CA) at $25 \mathrm{~V}$ for $25 \mathrm{~min}$ (Dry transfer). The blots were blocked for $1 \mathrm{~h}$ at room temperature (RT) in 5\% non-fat dry milk in TBS containing $0.1 \%$ Tween-20 (TBS-T), and incubated with anti-PR (1:200) and anti-HIF-1 $\alpha$ (1:150) antibodies overnight at $4^{\circ} \mathrm{C}$. The blots were washed 3 times with TBS-T and incubated with secondary antibody for $1 \mathrm{~h}$ at RT. The blots were then washed 7 times $(8 \mathrm{~min}$ each) with TBS-T and immunoreactive bands were visualized using an ECL plus detection kit (Amersham, Pharmacia Biotech, Arlington Heights, IL). Membranes were stripped and re-blotted for $\beta$-actin (Sigma, St. Louis, MO), which was used as a control for protein loading.

RNA extraction and RT-PCR. Cells were treated with progestin $(10 \mathrm{nM}) \pm 100 \mu \mathrm{M} \mathrm{YC}-1$ for $6 \mathrm{~h}$ at $37^{\circ} \mathrm{C}$. Ultraspec RNA reagent $(1 \mathrm{ml})$ (Biotecx Products, Oxon, UK) was added to each plate and RNA was purified as described by the manufacturer. Pellets containing purified RNA were re-suspended in DEPC treated water. RNA was DNase treated prior to RT-PCR which was performed as described previously (23). VEGF and $\beta$-actin primer pairs were purchased from $R \& D$ Systems, Inc.; DNA sequences for these are propriety. Forward 5'-3': ATGAGAAGTATGACAACAGCC, and reverse 5'-3': TGAGTCCTTCCACGATACC were used for GAPDH. The following cycle was employed; $60^{\circ} \mathrm{C}$ for $30 \mathrm{~min}$ for cDNA synthesis, $94^{\circ} \mathrm{C}$ for 2 min for denaturing and 40 cycles of $94^{\circ} \mathrm{C}$ for $15 \mathrm{sec}, 50-55^{\circ} \mathrm{C}$ for $30 \mathrm{sec}$ and $68^{\circ} \mathrm{C}$ for $1 \mathrm{~min}$ for amplification. Final extension was for $7 \mathrm{~min}$ at $68^{\circ} \mathrm{C}$.

$D M B A$-induced mammary tumors. Intact virgin female 40-45 day old Sprague-Dawley rats (Harlan Sprague-Dawley, Indianapolis, IN) were housed according to the guidelines of the Association for Assessment and Accreditation of Laboratory Animal Care under conditions of 12-h light/dark cycles and ad libitum access to food and water. All surgical and experimental procedures were in accordance with the 'Guide for Care and Use of Laboratory Animals' (NIH publication 85-23). Animals were given a single dose of $20 \mathrm{mg}$ of DMBA in peanut oil via gavage on day 0 . On day 30 , animals were anesthetized and MPA pellets were implanted subcutaneously on the dorsal surface (7). On day 68 , YC-1 (3.75 mg/day) (18), or vehicle, was administered to animals via tail vein injection for 5 days. Animals were palpated and tumors measured 2-3 times weekly. Mammary tumor tissues were collected at the time of sacrifice for immunohistochemistry (IHC) analysis. In order to determine blood vessel perfusion within tumors, animals were injected with $0.5 \mathrm{mg}$ Texas red-tomato lectin conjugate $10 \mathrm{~min}$ prior to sacrificing, as described (24).

Xenograft tumor study. Five to six week old female athymic nu/nu mice, purchased from Harlan Sprague-Dawley, Inc., were 
housed in a laminar airflow cabinet under specific pathogenfree conditions. Nude mice were inoculated with 17- $\beta$-estradiol pellets (60-day timed release, $1.7 \mathrm{mg}$ ) 24-48 h before implantation of T47-D or BT474 cells in both flanks as described previously (8). In this model tumor cells initially grow but then spontaneously regress and the regression is rescued with progestins (8). In the experiments reported in this study, when tumors regressed to approximately $50 \%$ of their peak volume following tumor cell injection (6-10 days), MPA pellets (10 mg/60-day release) were implanted. Once tumor volume reached $80-120 \mathrm{~mm}^{3}$, animals received 10 daily treatments of YC-1 (600 $\mu \mathrm{g} / \mathrm{mouse}$, i.p.) (18), or vehicle alone. Tumor volume and animal weights were measured every 3 days. At the end of the experiment, animals were sacrificed and tumors collected $2 \mathrm{~h}$ following final treatment with YC-1 for IHC analysis.

Histology and immunohistochemisty. For both rat and mouse tumors, tissues were fixed overnight in $4 \%$ paraformaldehyde and processed for paraffin infiltration and embedding. Sections (5 $\mu \mathrm{m})$ were mounted on ProbeOn Plus microscope slides (Fischer Scientific, Inc., Pittsburgh, PA) and routinely stained with hematoxylin and eosin (H\&E) or prepared for immunohistochemical labeling. Prior to immunohistochemistry, sections were dewaxed in xylene, rehydrated through graded concentrations of ethanol, rinsed (wash buffer, Dako Carpinteria, CA) prior to immersion and heated in $10 \mathrm{mmol} / \mathrm{l}$ citrate buffer $(\mathrm{pH} \mathrm{6.0)}$ ) for $20 \mathrm{~min}$ for heat-induced epitope retrieval. This tissue treatment was performed for PR, ER $\alpha, \mathrm{ER} \beta, \mathrm{CD} 34$ and VEGF immunolabeling. Slides were cooled for $20 \mathrm{~min}$, treated with $3 \% \mathrm{H}_{2} \mathrm{O}_{2}$ (to inactivate endogenous peroxidase activity) and rinsed prior to incubation with $5 \%$ bovine serum albumin for $20 \mathrm{~min}$. Sections were then incubated for $60 \mathrm{~min}$ at room temperature with each of the following antibodies: anti-PR antibody [1:50 dilution of a rabbit anti-human PR polyclonal antibody (A0098), Dako], anti-ER $\alpha$ [1:300 dilution of a rabbit anti-ER $\alpha$ polyclonal antibody (sc-542), Santa Cruz Biotechnology, Inc., Santa Cruz, $\mathrm{CA}$, anti-ER $\beta$ [1:50 dilution of a mouse anti-ER $\beta$ monoclonal antibody (MCA1974s) AbD Serotec, Raleigh, NC], anti-CD34 (1:100 dilution of a goat anti-CD34 polyclonal antibody), and an anti-VEGF antibody [1:100 dilution of a rabbit anti-VEGF polyclonal antibody (sc-152); Santa Cruz Biotechnology, Inc.]. Sections were then washed, incubated for $30 \mathrm{~min}$ with a biotinylated secondary antibody [rabbit anti-mouse IgG (Dako) for anti-ER $\beta$ labeled sections and a rabbit anti-goat IgG (Dako) for the anti-CD34 probed sections] and then for $30 \mathrm{~min}$ with a streptavidin-linked horseradish peroxidase product (Dako). Sections for PR, ER $\alpha$ and VEGF were incubated with EnVision, a horseradish peroxidase-labeled polymer conjugated to antirabbit antibodies (Dako). Bound antibodies were visualized following incubation with 3,3'-diaminobenzidine solution (0.05\% with $0.015 \% \mathrm{H}_{2} \mathrm{O}_{2}$ in PBS; Dako) for 3-5 min. Sections were counterstained with Meyer's hematoxylin, dehydrated, and coverslipped for microscopic examination.

Texas red conjugated-tomato lectin. Sections $(8 \mu \mathrm{m})$ of frozen tumors were made using a cryostat. After rinsing, sections were incubated with $4 \%$ paraformaldehyde, rinsed again, and mounted with DAPI (Vectashield Hardset with DAPI, Vector Lab, Burlingame, CA) and coverslipped. In order to visualize
Texas red-labeled tomato lectin staining, samples were imaged with a $590 \mathrm{~nm}$ bandpass filter at 1/2 second exposure.

Statistical analysis. For VEGF analysis, data were analyzed by one-way ANOVA. Data were checked for normality and homogeneity of variance. Since a number of analyses did not satisfy these assumptions, data were ranked and ANOVA performed as outlined by Conover and Iman (25). Fisher's protected least significant difference (LSD) was performed to determine treatment differences, as suggested by Chew (26). All significance was based on the ranked transformations; however treatment values were presented as actual values. For DMBA studies, a difference in the growth curve of tumor size was compared via t-test. For nude mice studies, points along the tumor volume curve were compared via one-way ANOVA. FoveaoPro 3.0 ${ }^{\circledR}$ software analysis was used to determine positive staining by area in immunohistochemical studies. One-way ANOVA was used to statistically compare VEGF, CD34, and PR staining differences among experimental groups. For all statistical comparisons, $\mathrm{p}<0.05$ was regarded as statistically significant.

\section{Results}

YC-1 reduces cell viability of human breast cancer cells in a concentration dependent manner. T47-D and BT-474 cells were treated with increasing doses of YC-1 for 18 and cell viability monitored using the SRB assay (Fig. 1A). YC-1 effectively reduced cell viability in a concentration-dependent manner in a similar fashion to its effect on prostate cancer cells (17). In keeping with a previous study (17), we used a dose of $100 \mu \mathrm{M}$ YC-1 for subsequent in vitro analysis that involved 6-18 h exposure to the drug. Since YC-1 was extremely potent against BT- 474 cells at this concentration, we performed subsequent in vitro studies using T47-D cells in an effort to study the molecular mechanisms underlying the effects of YC-1.

YC-1 inhibits progestin-stimulated secretion of VEGF from T47-D cells. To determine whether YC-1 plays a role in progestin-stimulated secretion of VEGF from human breast cancer cells, T47-D cells were incubated for $30 \mathrm{~min}$ with 10- or $100 \mu \mathrm{M}$ YC-1 or $1 \mu \mathrm{M}$ anti-progestin RU-486 [anti-progestin (21-23)]. Following this initial incubation, $10 \mathrm{nM}$ MPA (most commonly used synthetic progestin in HRT) or $10 \mathrm{nM}$ progesterone was added for $18 \mathrm{~h}$ and VEGF secreted into the culture medium was quantified by ELISA. As reported previously by us (21-23), expression of VEGF was 3- to 4-fold higher in MPA and progesterone-treated T47-D cells compared with controls; VEGF induction was completely inhibited by a 100 -fold excess of RU-486, indicating the involvement of PR (Fig. 1B). Interestingly, while $10 \mu \mathrm{M}$ was without effect, $100 \mu \mathrm{M}$ YC-1 completely inhibited the induction of VEGF by progestin in T47-D cells in the time frame tested (Fig. 1B and data not shown). YC-1 also reduced basal levels of VEGF secretion from T47-D breast cancer cells, most likely by inhibiting HIF-1 $\alpha$, which is the major transcription factor required for VEGF induction, though this remains to be proven. Importantly, YC-1 also blocked the effect on VEGF secretion of other synthetic progestins used in HRT, including norethindrone and norgestrel (Fig. 1C). 
$Y C-1$ inhibits progression of MPA-dependent human breast cancer xenografts in nude mice. We previously developed a mouse xenograft model for identifying and characterizing factors that promote or prevent progestin-accelerated breast cancer (8). In the present study we used this model to examine the effects of YC-1 on growth of MPA-stimulated T47-D xenograft tumors. In this experimental design (Fig. 2A), xenograft tumors were allowed to grow to a volume of $80-120 \mathrm{~mm}^{3}$, after which tumor-bearing mice were treated with YC-1 [600 $\mu \mathrm{g} / \mathrm{mouse} /$ day (18)] for 10 days. Tumor volume and animal weight were measured every third day throughout the experiment. Fig. 2A shows clearly that YC-1 inhibited growth and caused regression of T47-D xenograft tumors. At the chosen

A

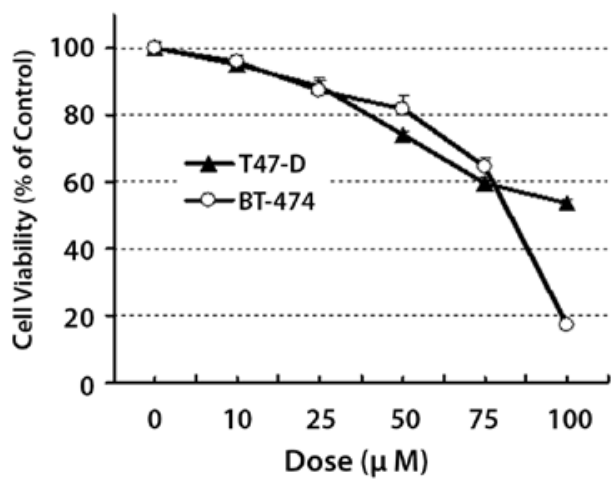

dose level, YC-1 was well tolerated and no signs of toxicity were detected in YC-1-treated mice (data not shown). Similar experiments conducted using nude mice bearing xenograft tumors derived from tamoxifen-resistant Her-2-neu enriched BT-474 breast cancer cells (27) showed that YC-1 strongly and rapidly inhibited growth of BT-474 tumor xenografts that were exposed to the natural hormone progesterone (data not shown).

Immunohistochemical studies were performed on MPAexposed T47-D xenograft tumors from YC-1 and vehicle-treated mice. Tissues for these studies were isolated from animals sacrificed $2 \mathrm{~h}$ after the final injection with YC-1. As expected, VEGF staining was higher in tumors from MPA-treated mice, and exposure to YC-1 reduced VEGF expression by a statistically significant amount (Fig. 2B and C). Although the difference was not statistically significant, YC-1 also appeared to reduce expression of CD34 in tumors from MPA-treated mice (Fig. 2C; $16 \pm 2.3, \mathrm{n}=3, \mathrm{MPA}+\mathrm{YC}-1$ vs. $20 \pm 5.5, \mathrm{n}=5, \mathrm{MPA}$ ); this finding is consistent with the possibility that $\mathrm{YC}-1$ inhibits angiogenesis in T47-D xenograft tumors under the chosen experimental conditions.

$Y C-1$ reduces $P R$ levels in vivo. Immunohistochemical analysis of PR expression was also carried out on T47-D xenograft tumors from YC-1 treated mice. Fig. 2B and C (right panel) shows that PR levels were significantly lower in tumors from mice treated with MPA or MPA/YC-1 than in tumors

B

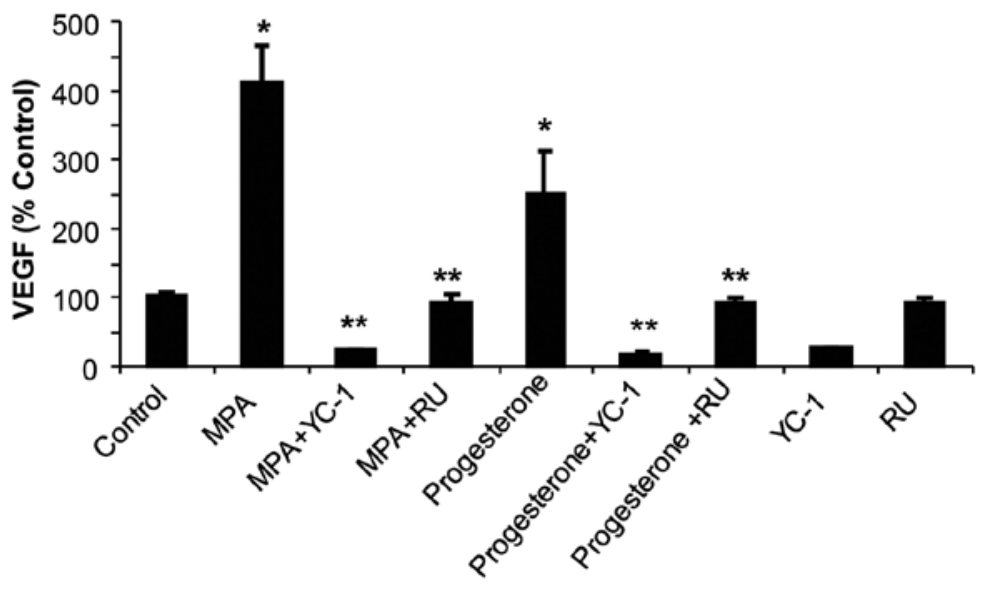

C

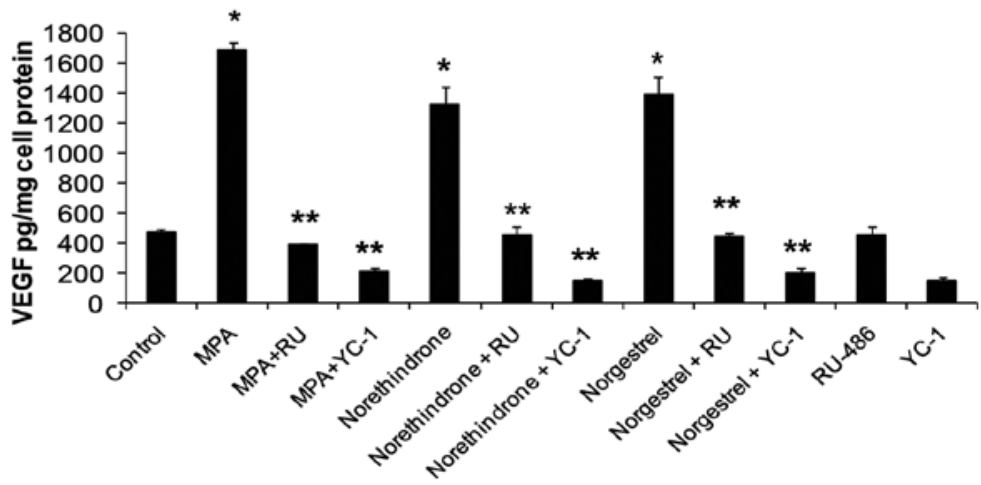

Figure 1. YC-1 inhibits cell viability and progestin-induced VEGF secretion in human breast cancer cells (n=6 for each concentration). (A), T47-D and BT-474 cells were treated with indicated concentrations of YC-1 for $18 \mathrm{~h}$ and cell viability was determined using the SRB assay. ${ }^{*}$ Significantly different from control ( $\mathrm{p}<0.001$, ANOVA). (B), T47-D cells were pre-treated for $30 \mathrm{~min}$ with $1 \mu \mathrm{M}$ RU-486, or $100 \mu \mathrm{M}$ YC-1 and then treated with $10 \mathrm{nM}$ progesterone or MPA or with synthetic progestins (C). Media was collected after 16-18 h and analyzed for VEGF using ELISA as described in Materials and methods ( $\mathrm{n}=3-12$ ). One-way ANOVA was used to statistically analyze data. * Significant induction compared with control. ${ }^{* *}$ Significant inhibition compared with appropriate progestin control, $\mathrm{p}<0.05$. The control value for VEGF in Fig. 2A represents $496 \pm 51 \mathrm{pg} / \mathrm{mg}$ cellular protein. 
A

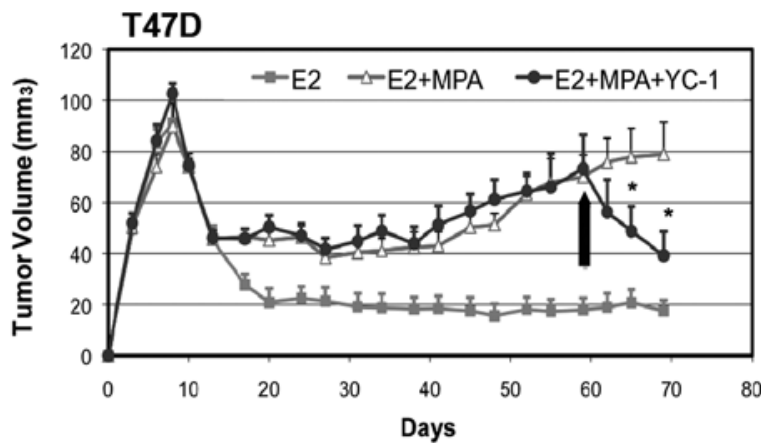

from control animals treated with only E2 [all animals were administered E2 by implant to facilitate initial tumor formation; however E2 alone does not lead to tumor growth under the conditions used for growing P-dependent tumors $(8,27)]$. The difference in PR expression between each of these three groups was statistically significant, suggesting that different mechanisms are responsible for repression of PR by YC-1 and MPA. Additional studies showed that the expression of ER $\alpha$ and ER $\beta$ is not modulated by YC- 1 or MPA in the context of this mouse xenograft tumor model (data not shown).
B

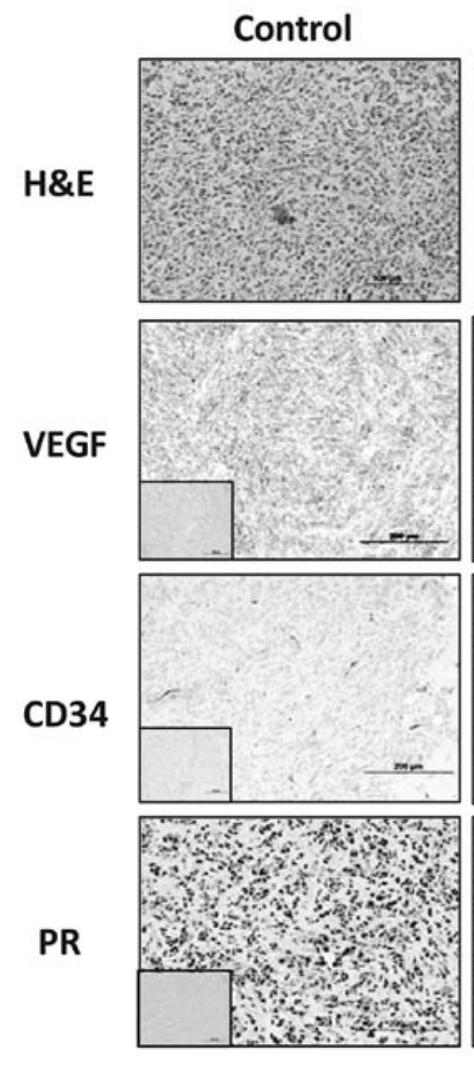

C

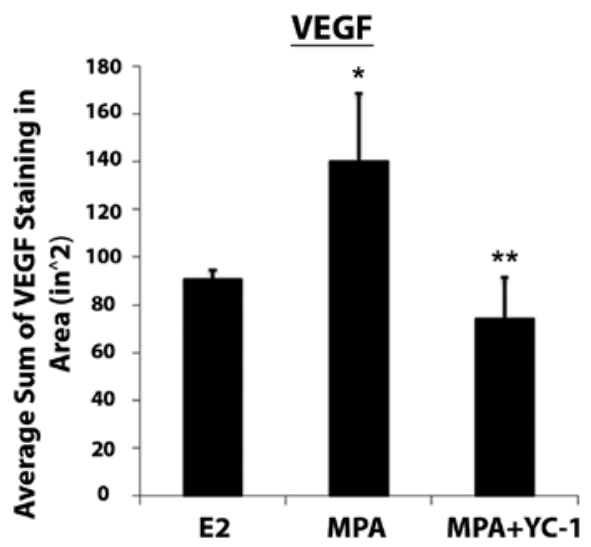

MPA

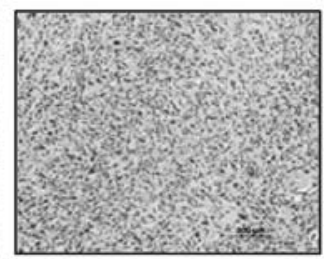

\section{MPA + YC-1}
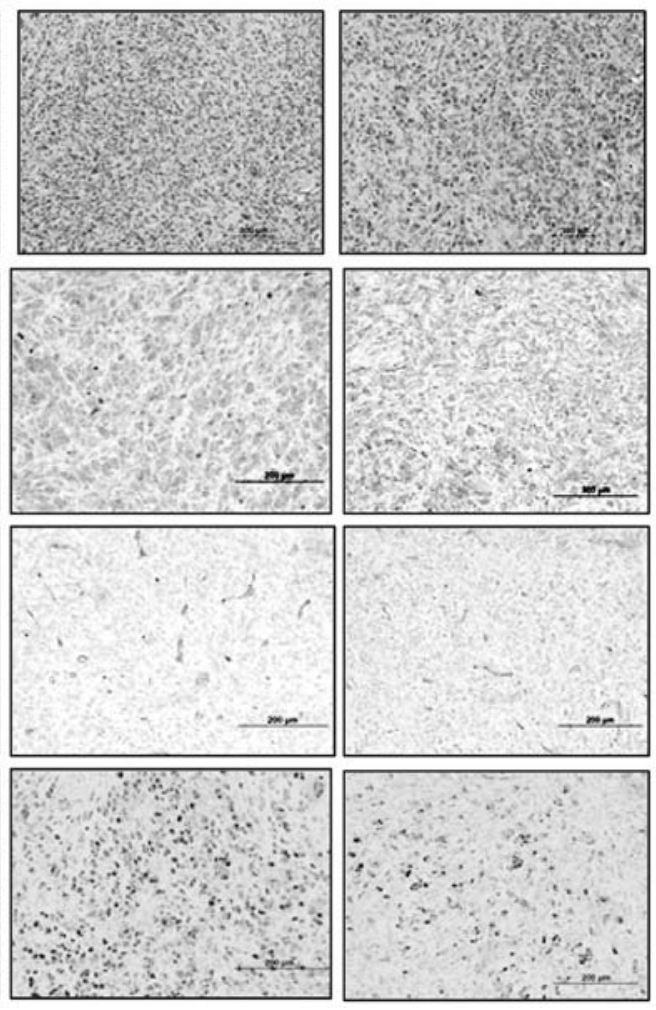

PR

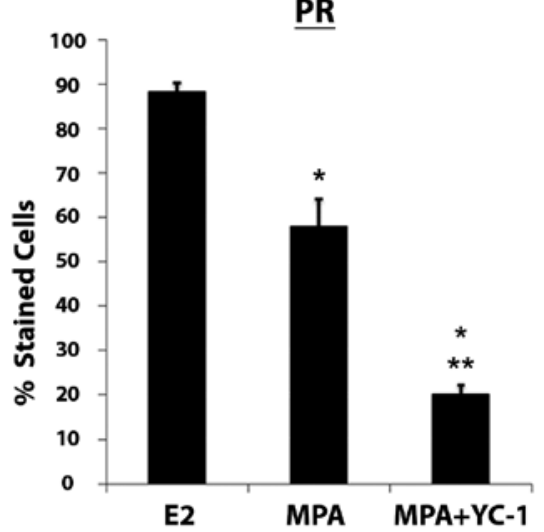

Figure 2. YC-1 inhibits progression of MPA-dependent breast cancer xenograft tumors in nude mice. (A), Xenograft tumors derived from T47D-cells were grown as described in Materials and methods. Tumor bearing mice were treated with YC-1 or vehicle alone (i.p., arrow) as described in Materials and methods (n=5, 10 tumors per group). *Significantly different from controls as analyzed by one-way ANOVA, p<0.05. (B), Immunohistochemical analysis of MPA-dependent, T47D-derived tumors. H\&E, VEGF, CD34 and PR expression were analyzed in control (mice containing $\mathrm{E}_{2}$ pellets), untreated ( $\mathrm{E}_{2}+\mathrm{MPA}+\mathrm{vehicle}$ and treated $\left(\mathrm{E}_{2}+\mathrm{MPA}+\mathrm{YC}-1\right)$ tumors. Collected tumor tissues were sectioned and immunostained for the proteins shown, as described in Materials and methods. Insets represent negative controls with no primary antibody staining for each antibody. Original magnification, x20. (C), Quantification of VEGF and PR immunostaining from tissues analyzed in (B). Four fields from each tumor section were analyzed to control for variation due to cellularity (control, $\mathrm{n}=3$ tumors; MPA + vehicle, $n=3$ tumors; MPA + YC-1, $n=4$ tumors). VEGF staining (left panel): positive VEGF staining was quantified as the number of VEGF-positive pixels in different fields using FoveaoPro 3.0 analysis software. Error bars represent SEM. *Statistical significance compared to control (p<0.001; ANOVA). ${ }^{* *}$ Statistical significance compared to MPA + vehicle ( $\mathrm{p}<0.001$; ANOVA). PR staining (right panel) percentage of positive cells in 6 fields of each section was counted. Error bars represent SEM ( $\left.{ }^{*} \mathrm{p}<0.001\right)$. 


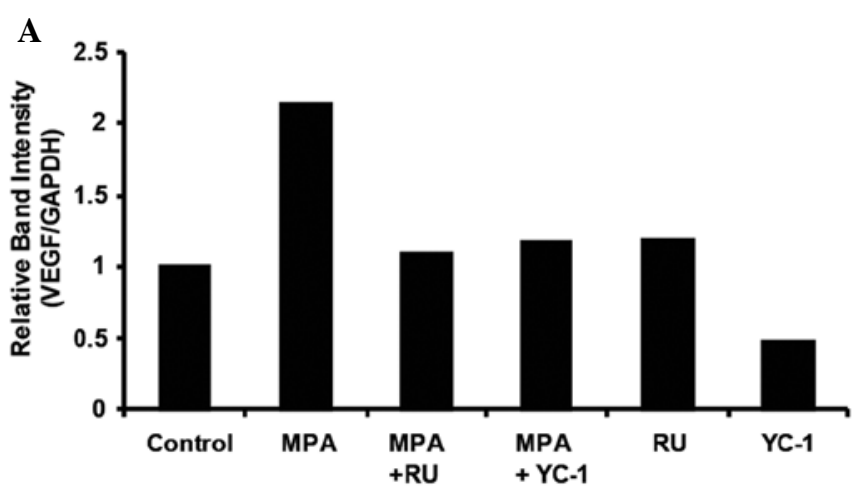

B

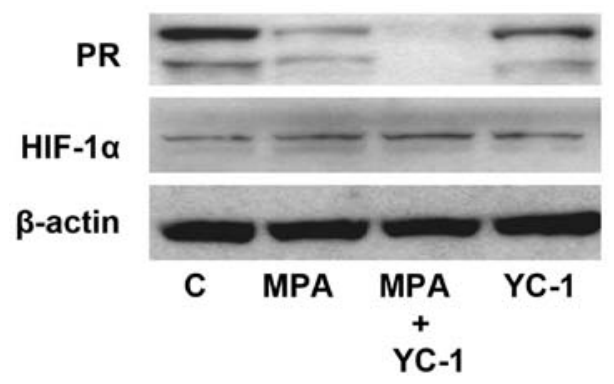

Figure 3. (A), YC-1 inhibits progestin-induced VEGF transcription in T47-D human breast cancer cells. Cells were treated with $100 \mu \mathrm{M} \mathrm{YC}-1$ for $6 \mathrm{~h}$ and RT-PCR was used to detect VEGF mRNA using $1 \mu \mathrm{g}$ of RNA from treated cells, as described in Materials and methods. Results shown are mean of two experiments. (B), Western blot analysis of T47-D cell nuclear extract. T47-D cells were treated with $10 \mathrm{nM}$ MPA alone or in the presence of $1 \mu \mathrm{M} \mathrm{RU}-486$, $100 \mu \mathrm{M}$ YC-1 or $100 \mu \mathrm{M} 2 \mathrm{ME} 2$, or with inhibitors alone for $6 \mathrm{~h}$. Nuclear extracts were collected as described in Materials and methods and $20 \mu \mathrm{g}$ of protein was loaded and probed for HIF-1 $\alpha$, progesterone receptor A and B and $\beta$-actin. In the progesterone receptor (PR) lanes, upper band represents PRB while the lower band represents PRA. RU $=$ RU-486.

$Y C-1$ reduces $P R$ levels in vitro and inhibits progestindependent transcription of the VEGF gene. In order to confirm in vivo observations that $\mathrm{YC}-1$ downregulates VEGF and $\mathrm{PR}$, we conducted in vitro assays and examined the effect of YC-1 on transcription of VEGF mRNA in MPA-treated cells. For this study, T47-D cells were incubated for $30 \mathrm{~min}$ in the presence of $100 \mu \mathrm{M}$ YC-1 or $1 \mu \mathrm{M}$ RU-486, followed by $6 \mathrm{~h}$ with $10 \mathrm{nM}$ MPA (23). YC-1 and RU-486 completely blocked progestin-stimulated VEGF transcription (Fig. 3A). The effect of YC-1 on levels of PR and HIF-1 $\alpha$ was also determined in treated and untreated T47-D cells. Fig. 3B demonstrates that exposure to YC-1 for $6 \mathrm{~h} \pm$ MPA resulted in reduced expression and/or stability of PR in T47-D cells. A similar effect was observed in cells exposed to progestins which activate PR [coupled to receptor degradation (30) and stimulates secretion of VEGF (21-23)]. PR expression was lower in those cells treated with a combination of MPA and YC-1 compared with cells treated with only YC-1, suggesting different mechanisms of action. Such an effect was also observed in vivo (see above). YC-1 did not promote degradation of HIF-1 $\alpha$ in T47-D breast cancer cells under the conditions employed, indicating that PR loss did not occur as a result of a generalized cytotoxic effect of YC-1. $\beta$-actin was used as loading control.

YC-1 inhibits progression of DMBA-induced MPA-driven mammary tumors and reduces expression of VEGF in tumor cells. Our previous studies showed that MPA stimulates expres- sion and secretion of VEGF and accelerates the development of DMBA-induced mammary tumors in female Sprague-Dawley rats (7). In the present study we sought to determine whether YC-1 inhibits mammary tumor progression in this model system. DMBA was administered to female Sprague-Dawley rats (45-50 days old), MPA pellets ( $25 \mathrm{mg}, 60$-day release) were implanted subcutaneously on day 28 and tumors were allowed to develop. On day 68, tumor-bearing animals were treated with YC-1 (3.75 mg/rat/day) as described in Materials and methods. YC-1 administration continued for 5 consecutive days; control animals were treated with vehicle (Fig. 4A). At the commencement of YC-1 treatment tumors ranged in size from 2 to $100 \mathrm{~mm}^{3}$ (tumors grow at different rates in this animal model system and new tumors develop at various times resulting in variations in size). Animals were weighed to monitor drug toxicity. Tumors were measured and palpated daily during the course of treatment and 2-3 times per week after the cessation of daily injections until the end of the study. As expected a continuous increase in tumor size occurred in vehicle-treated animals, while YC-1 inhibited growth and progression of tumors with an original size up to $100 \mathrm{~mm}^{3}$, the largest size of tumor treated (Fig. 3A). The effect of YC-1 lasted for 20 days after the last injection of the drug, at which point the experiment was terminated and tumors removed for immunohistochemical analysis. Based on animal weight, YC-1 was not toxic at this dose (data not shown).

Although the histology of DMBA-induced mammary tumors from animals administered YC-1 did not differ greatly from those given vehicle, immunohistochemical analysis showed a significant reduction in VEGF staining in tumors obtained from YC-1 treated animals (Fig. 4B, upper panel), together with a corresponding decrease in CD34 staining (Fig. 4B, middle panel), suggesting a reduced number of blood vessels. The reduction in CD34-positive blood vessels was not statistically significant; however, blood vessels in tumors collected from YC-1 treated rats were also smaller in diameter, further suggesting a reduced blood supply compared with tumors from control animals not administered YC-1. This was confirmed by a significantly reduced rate of blood perfusion in tumors from YC-1-treated rats (Fig. 4B, lower panel; see Materials and methods for experimental details). As noted above, YC-1 had no effect on the levels of expression of PR, ER $\alpha$ or ER $\beta$ in DMBA-induced mammary tumors in rats (data not shown). However, receptor expression was examined at just one time point, twenty days after the last injection of YC-1, which may allow PR to recover. Consequently additional studies of hormone receptor expression in YC-1 treated DMBA-initiated rats are needed.

\section{Discussion}

Recently a number of studies and clinical trials have shown that HRT which contains a progestin component is associated with a higher risk of metastatic breast cancer than HRT lacking progestin (1-4). Anti-progestins, such as RU-486, cannot be used to mitigate this risk, because of their lack of specificity and severe adverse effects (9). Because a large number of postmenopausal women who are already at significant breast cancer risk are routinely exposed to progestin-containing HRT, there is an urgent need to develop viable alternative strategies 
that can be rapidly developed for clinical use, to lower the risk of or even prevent breast cancer. Here we report the results of preclinical studies in which we evaluated the potential of YC-1, a recently developed anticancer agent, to prevent the progestin-dependent progression of human breast cancer.

Progestins induce VEGF in breast cancer cells (29) in a PR-dependent manner and cause tumor progression and metastasis in animal models $(8,27)$. VEGF expression within tumor cells is under the control of a number of essential transcription factors, one of the most important being HIF-1 $\alpha$, which regulates survival genes, including VEGF $(14,15)$. Higher levels of HIF1 $\alpha$ and VEGF are associated with increased risk of tumor metastasis $(27,30)$. Interestingly, recent studies also provide evidence that HIF- $1 \alpha$ is involved in hormone mediated regulation of VEGF $(13,31)$. Thus HIF-1 $\alpha$ appears to play a central role in the regulation of VEGF by steroid hormones in reproductive tissues, though a direct role of HIF-1 $\alpha$ in

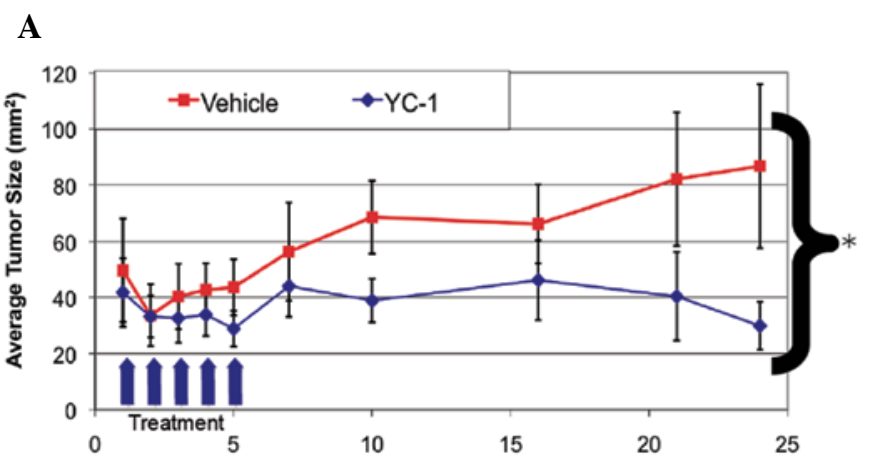

nuclear receptor mediated events remains to be established. Since the induction of VEGF by progestins is well established in breast cancer cells $(8,9,21-23,29)$ and it is possible that one mechanism through which this occurs involves HIF-1 $\alpha$, we undertook studies using both naturally-occurring and synthetic progestins and found that YC-1 inhibits induction of VEGF in both T47-D and BT-474 cells. Synthetic progestins which are used in various formulations worldwide as HRT all induce VEGF and have the potential to promote tumor metastasis (27). Although previous studies have shown that YC-1 inhibits angiogenesis (32), ours is the first to demonstrate that it blocks progestin-dependent angiogenesis. We propose therefore that YC-1 could be a useful drug which might be used clinically to prevent progestin-dependent tumor growth and metastasis. To lend further support to the notion that YC-1 might prove effective against progestin-dependent breast disease, we found that it also suppressed PR levels in breast cancer cells, both in vitro and in vivo. The effect of YC-1 could therefore be 2-fold; inhibition of HIF-1 $\alpha$ and downregulation of PR, making it a uniquely suitable small molecule drug for combating those forms of breast cancer which are largely dependent on the actions of progestins to stimulate the production of VEGF. Further studies are required to determine the molecular mechanism through which YC-1 brings about the loss of PR, since it is possible that HIF- $1 \alpha$ regulates PR and YC-1 shuts down PR synthesis due to loss of HIF-1 $\alpha$ activity.

This study demonstrates that YC-1 effectively inhibits the growth of progestin-accelerated xenograft tumors derived from T47-D or BT-474 cells in mice and DMBA-induced tumors in rats, supporting the notion that it possesses significant

Days After Treatment

B

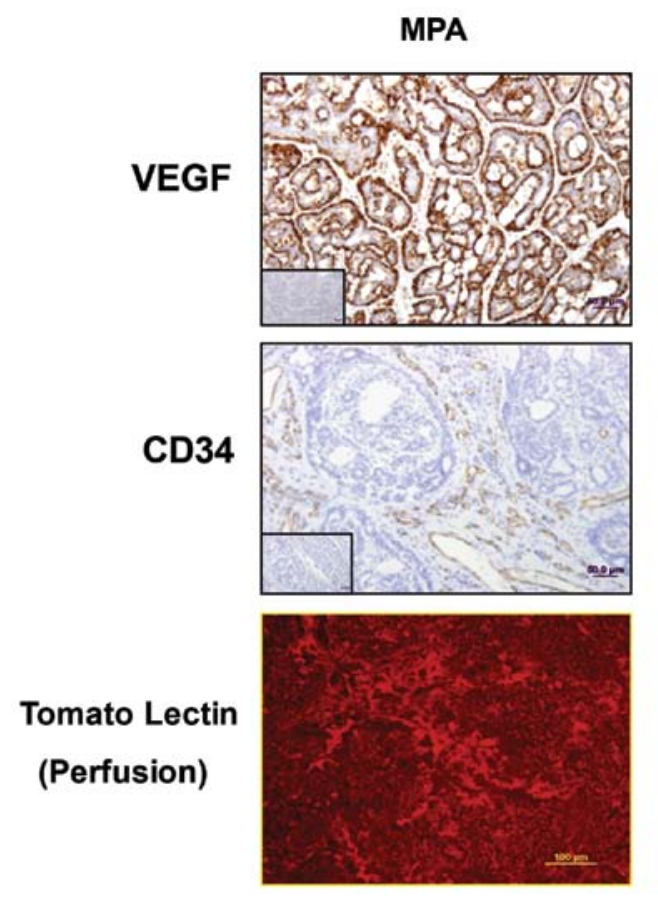

MPA + YC-1
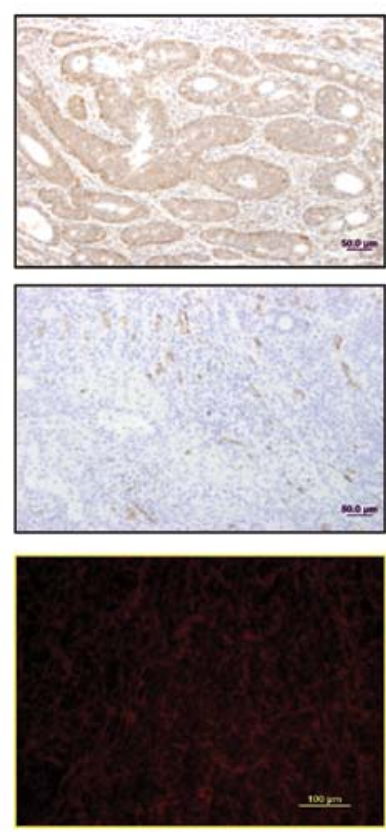

Figure 4. (A), YC-1 suppresses progestin-induced progression of DMBA-induced mammary tumors in rats. Sprague-Dawley rats were treated with $20 \mathrm{mg}$ DMBA via gavage. After 4 weeks, $25 \mathrm{mg} / 60$-day timed release pellets of MPA were implanted as described in Materials and methods. Beginning on day $68,3.75 \mathrm{mg}$ YC-1, or vehicle, was administered to animals for a further 5 days via tail vein injection. Error bars represent SEM, $n=3$ animals for control group ( 7 tumors) and 4 animals in the YC-1 treatment group (9 tumors). "Significant difference between control and YC-1 treated group as analyzed by t-test, $\mathrm{p}<0.05$. (B), Immunohistochemical analysis of tumor tissues from DMBA animal studies shown in (A). Collected tumor tissues were sectioned and immunostained for the designated protein as described in Materials and methods. Insets represent no antibody control. Original magnification, x20. Bar represents $50 \mu \mathrm{m}$ except in figures containing Tomato lectin staining, where bar represents $100 \mu \mathrm{m}$. 
potential as an anti-breast cancer agent in vivo. Although the exact mechanism by which YC-1 exerts its in vivo effects has not yet been established, we propose that YC-1, by inhibiting progestin-mediated VEGF-dependent angiogenesis, reduces blood flow to xenograft tumors in these experimental model systems. Alternatively, YC-1-mediated downregulation of PR could play a key role in the anti-tumor effectiveness of this HIF-1 $\alpha$ inhibitor, a possibility which remains to be tested. Since ER levels were not affected by YC-1, it is likely that combination therapy using $\mathrm{YC}-1$ and an anti-estrogen might be more effective than therapy using either compound alone, another scenario that requires further study.

In the Sprague-Dawley rat DMBA-induced progestinaccelerated tumor model, YC-1 prevented the progression of progestin-dependent tumors and inhibited expression of VEGF, but did not downregulate PR. However, since these tumors were analyzed several days after the end of YC-1 treatment it is possible that PR was re-expressed in tissues over time. While there was no significant reduction in the number of blood vessels in tumors from YC-1-treated animals, blood vessels were smaller and had reduced capacity for perfusion (Fig. 4B), a phenomenon we also observed in other experimental models (24,33). It therefore appears that YC-1 inhibits tumor growth in the DMBA-induced progestin-accelerated tumor primarily by downregulating VEGF. However, additional analysis of the kinetics of PR expression during studies such as these is warranted.

In conclusion, this study provides strong evidence that YC-1, a potent HIF-1 $\alpha$ inhibitor, may be a useful pharmacologic agent which might be used to treat and possibly prevent PR-dependent breast cancer as a result of promoting PR loss. This could be especially valuable in a clinical context to mitigate the increased breast cancer risk associated with progestin-containing HRT.

\section{Acknowledgements}

This work was supported by NIH grants R56CA-86916 and 1F31CA130167; COR award from College of Veterinary Medicine, and Research Funds from RADIL, University of Missouri. S.M.H. is the Zalk Missouri Professor of Tumor Angiogenesis.

\section{References}

1. Ross R, Paganini-Hill A and Pike MC: Effect of hormone replacement therapy on breast cancer risk: estrogen versus estrogen plus progestin. J Natl Cancer Inst 92: 328-332, 2000.

2. Schairer C, Lubin J, Troisi R, Sturgeon S, Brinton L and Hoover R: Menopausal estrogen and estrogen progestin replacement therapy and breast cancer risk. JAMA 283: 485-491, 2000

3. Li CI, Malone KE, Porter PL, Weiss NS, Tang MT, CushingHaugen KL and Daling JR: Relationship between long durations and different regimens of hormone therapy and risk of breast cancer. JAMA 289: 3254-3263, 2003.

4. Chlebowski RT, Anderson GL, Gass M, Lane DS, Aragaki AK, Kuller LH, Manson JE, Stefanick ML, Ockene J, Sarto GE, Johnson KC, Wactawski-Wende J, Ravdin PM, Schenken R, Hendrix SL, Rajkovic A, Rohan TE, Yasmeen S, Prentice RL and WHI Investigators: Estrogen plus progestin and breast cancer incidence and mortality in postmenopausal women. JAMA 304: 1684-1692, 2010.

5. Liang Y, Wu J, Stancel GM and Hyder SM: p53-dependent inhibition of progestin-induced VEGF expression in human breast cancer cells. J Steroid Biochem Mol Biol 93: 173-182, 2005.
6. Liang Y and Hyder SM: Proliferation of endothelial and tumor epithelial cells by progestin-induced vascular endothelial growth factor from human breast cancer cells: paracrine and autocrine effects. Endocrinology 146: 3632-3641, 2005.

7. Benakanakere I, Besch-Williford C, Schnell J, Brandt S, Ellersieck MR, Molinolo A and Hyder SM: Natural and synthetic progestins accelerate 7,12-dimethylbenz[a]anthracene-initiated mammary tumors and increase angiogenesis in Sprague-Dawley rats. Clin Cancer Res 12: 4062-4071, 2006.

8. Liang Y, Besch-Williford C, Brekken RA and Hyder SM: Progestin-dependent progression of human breast tumor xenografts: a novel model for evaluating antitumor theraputics. Cancer Res 67: 9929-9936, 2007.

9. Horwitz K: The molecular biology of RU-486. Is there a role for anti-progestins in the treatment of breast cancer? Endocr Rev 12: 146-163, 1992.

10. Otrock ZK, Hatoum HA, Awada AH, Ishak RS and Shamseddine AI: Hypoxia-inducible factor in cancer angiogenesis: structure, regulation and clinical perspectives. Crit Rev Oncol Hematol 70: 93-102, 2009.

11. Carmeliet P, Dor Y, Herbert J-M, Fukumura D, Brusselmans K, Dewerchin M, Neeman M, Bono F, Abramovitch R, Maxwell P, Koch CJ, Ratcliffe P, Moons L, Jain RK, Collen D and Keshet E: Role of HIF-1[alpha] in hypoxia-mediated apoptosis, cell proliferation and tumour angiogenesis. Nature 394: 485-490, 1998.

12. Forsythe JA, Jiang BH, Iyer NV, Agani F, Leung SW, Koos RD and Semenza GL: Activation of vascular endothelial growth factor gene transcription by hypoxia-inducible factor 1 . Mol Cell Biol 16: 4604-4613, 1996.

13. Shimizu T and Miyamoto A: Progesterone induces the expression of vascular endothelial growth factor (VEGF) 120 and Flk-1, its receptor, in bovine granulose cells. Anim Reprod Sci 102: 228-237, 2007.

14. Semenza GL: HIF-1: using two hands to flip the angiogenic switch. Cancer Metastasis Rev 19: 59-65, 2000.

15. Chun YS, Yeo EJ, Choi E, Teng CM, Bae JM, Kim MS and Park JW: Inhibitory effect of YC-1 on the hypoxic induction of erythropoietin and vascular endothelial growth factor in Hep3B cells. Biochem Pharmacol 61: 947-954, 2001.

16. Tulis DA, Durante W, Peyton KJ, Chapman GB, Evans AJ and Schafer AI: YC-1, a benzyl indazole derivative, stimulates vascular cGMP and inhibits neointima formation. Biochem Biophys Res Commun 279: 646-652, 2000.

17. Huang YT, Pan SL, Guh JH, Chang YL, Lee FY, Kuo SC and Teng CM: YC-1 suppresses constitutive nuclear factor-kappaB activation and induces apoptosis in human prostate cancer cells. Mol Cancer Ther 4: 1628-1635, 2005.

18. Yeo E-J, Chun YS, Cho YS, Kim J, Lee J-C, Kim M-S and Park J-W: YC-1: A potential anticancer drug targeting hypoxiainducible factor 1. J Natl Cancer Inst 95: 516-525, 2003.

19. Rubinstein LV, Shoemaker RH, Paull KD, Simon RM, Tosini S, Skehan P, Scudiero DA, Monks A and Boyd MR: Comparison of in vitro anticancer-drug-screening data generated with a tetrazolium assay versus a protein assay against a diverse panel of human tumor cell lines. J Natl Cancer Inst 82: 1113-1118, 1990.

20. Skehan P, Storeng R, Scudiero D, Monks A, McMahon J, Vistica D, Warren JT, Bokesch H, Kenney S and Boyd MR: New colorimetric cytotoxicity assay for anticancer-drug screening. J Natl Cancer Inst 82: 1107-1112, 1990.

21. Carroll CE, Ellersieck MR and Hyder SM: Curcumin inhibits MPA-induced secretion of VEGF from T47-D human breast cancer cells. Menopause 15: 570-574, 2008.

22. Hyder S, Murthry L and Stancel GM: Progestin regulation of vascular endothelial growth factor in human breast cancer cells. Cancer Res 58: 392-395, 1998.

23. Mafuvadze B, Benakanakere I and Hyder SM: Apigenin blocks induction of vascular endothelial growth factor mRNA and protein in progestin-treated human breast cancer cells. Menopause 17: 1055-1063, 2010.

24. Benakanakere I,Besch-Williford C,Ellersieck MR and Hyder SM: Regression of progestin-accelerated 7,12-dimethylbenz[a] anthracene-induced mammary tumors in Sprague-Dawley rats by p53 reactivation and induction of massive apoptosis: a pilot study. Endocr Relat Cancer 16: 85-98, 2009.

25. Conover W and Iman RL: Rank transformations as a bridge between parametric and nonparametric statistics. Am Stat 35: 124-129, 1981

26. Chew V: Comparison among treatment means and analysis of variance. Agricultural Research Service, USDA (ARS/H/6 Report), Washington, DC, 32-35, 1977. 
27. Liang Y, Benakanakere I, Besch-Williford C, Hyder RS Ellersieck MR and Hyder SM: Synthetic progestins induce growth and metastasis of BT-474 human breast cancer xenografts in nude mice. Menopause 17: 1040-1047, 2010.

28. Dennis AP, Lonard DM, Nawaz Z and O'Malley BW: Inhibition of the $26 \mathrm{~S}$ proteasome blocks progesterone receptor-dependent transcription through failed recruitment of RNA polymerase II. J Steroid Biochem Mol Biol 94: 337-346, 2005.

29. Hyder SM, Chiappetta C and Stancel GM: Pharmacological and endogenous progestins induce vascular endothelial growth factor expression in human breast cancer cells. Int J Cancer 92: 469-473, 2001.

30. Rundqvist $\mathrm{H}$ and Johnson RS: Hypoxia and metastasis in breast cancer. Curr Top Microbiol Immunol 345: 121-139, 2010.
31. Kazi A, Jones JM and Koos RD: Chromatin immunoprecipitation analysis of gene expression in the rat uterus in vivo: estrogen-induced recruitment of both estrogen receptor $\alpha$ and hypoxia-inducible factor 1 to the vascular endothelial growth factor promoter. Mol Endocrinol 19: 2006-2019, 2005.

32. Pan SL, Guh JH, Peng CY, Wang SW, Chang YL, Cheng FC, Chang JH, Kuo SC, Lee FY and Teng CM: YC-1 [3-(5'-hydroxymethyl-2'-furyl)-1-benzyindazole] inhibits endothelial cell functions induced by angiogenic factors in vitro and angiogenesis in vivo models. J Pharmacol Exp Ther 314: 35-42, 2005.

33. Liang Y, Besch-Williford C, Benakanakere I, Thorpe PE and Hyder SM: Targeting mutant p53 protein and the tumor vasculature: an effective combination therapy for advanced breast tumors. Breast Cancer Res Treat 125: 407-420, 2010. 